\title{
“Comparative Study of 'Intravaginal Misoprostol Alone' Versus 'Extra Amniotic Ethacridine Lactate Instillation Followed by Intravaginal Misoprostol' for Mid Trimester (13-20 Weeks) Termination of Pregnancy"
}

\author{
Gangwal Mamta ${ }^{1}$, Sharma Kamal Kant ${ }^{2}$, Bairwa Ramavatar ${ }^{3}$, \\ Dhaka Saroj ${ }^{4}$, Shashi Gupta ${ }^{5}$ \\ ${ }^{I}$ Medical Officer, Obs \& Gynae,23,Mayapuri Colony, Near Rakshak Marshal Art, Jagatpura, Jaipur \\ Rajasthan, India. \\ ${ }^{2}$ Medical Officer, 466 K Shyam Nagar School Ki Dhani Phulera. \\ ${ }^{3}$ Medical Officer, Medicine Dept. 23, Mayapuri Colony, Jagatpura, \\ ${ }^{4}$ Senior Resident, Basani Bairas,Tha-Laxamangarh, Dist.Sikar,Rajasthan \\ ${ }^{5}$ Professor Ex- Head Of Department, Obs \& Gynae, Sms Medical College, Jaipur \\ Department Of Obstetrics And Gynecology Mahila Chikitsalay,Sanganeri Gate, S.M.S. Medical College \\ Jaipur-302012 (Rajasthan) India
}

\begin{abstract}
:
Objective(s): To compare the efficacy, safety and induction-abortion interval of "intravaginal Misoprostol alone" versus "extra-amniotic Ethacridine lactate $0.1 \%$ followed by intravaginal Misoprostol" for mid-trimester (13-20 weeks) abortion.

Method(s): 60 women undergoing mid-trimester abortion were recruited for comperative study.They were devided into 2 groups. Group-A (30 cases) received intravaginal tab Misoprostol $600 \mu \mathrm{g}$ followed by $400 \mu \mathrm{g} 8$ hourly and Group-B (30 cases) received extra-amniotic Ethacridine lactate 0.1\% followed 6 hours later by intravaginal Misoprostol $400 \mu \mathrm{g} 3$ hourly until abortion occurred or upto 48 hours.

Result(s): Mean induction-abortion interval in Group-A was $24.9 \pm 10.83$ hours whereas $18.3 \pm 6.1$ hours in Group-B. In Group-A complete abortion occurred in $70 \%$ cases and in Group-B $83.33 \%$. Failure rate in GroupA was $6.67 \%$ while none in Group-B. Efficacy of abortion in Group-A was $93.33 \%$ while 100\% in Group-B. Side effects and complications were more common in Group-A than Group-B.

Conclusion(s) : Ethacridine-lactate followed by Misoprostol is definitely a better and effective method for midtrimester abortion rather than using Misoprostol alone.
\end{abstract}

Keyword(s): Intravaginal Misoprostol, Extra-amniotic Ethacridine lactate, mid-trimester abortion

\section{Introduction}

The majority ( 85 to $90 \%$ ) of abortions performed in the first trimester ${ }^{1}$. There is still a gradual increase in second trimester abortion because of the progress achieved in the field of fetal antenatal diagnosis. Mid trimester, abortion is more risky in terms of maternal morbidity and mortality. It has moral, social, emotional and technical issues. ${ }^{2}$ In the interest of mother's health and life under the MTP Act, mid trimester abortion performed by surgical or medical methods. Surgical method is loosing its popularity due to its inherent complications, need trained individuals and equipments and the advantages offered by medical methods. Now adays, majority of mid trimester abortions carried out medically. There are various medical regimes with variable success rates and complications. ${ }^{3} \mathrm{PGE}_{1}$ analogue Misoprostol has uterotonic effect and is used for the termination of pregnancy with great success. Misoprostol acts by causing cervical ripening and labour induction. ${ }^{4}$ Ethacridine lactate has a long history of use for mid-trimester abortion in our country. It works by endogenous production of prostaglandins by stripping of fetal membrane from the uterine decidua along with mechanical stimulation provided by catheter. ${ }^{5}$ Ethacridine lactate is safe and effective method for mid trimester termination of pregnancy that nullify its disadvantage of prolonged induction-abortion interval. Simultaneous use of two different drugs has a synergistic effect on uterine stimulation and reduces the induction-abortion interval. In this study, comparison has been done regarding efficacy, safety and induction-abortion interval of intravaginal Misoprostol alone versus extra-amniotic Ethacridine lactate $0.1 \%$ instillation followed by intravaginal Misoprostol for mid-trimester (13-20 wks) termination of pregnancy. 


\section{Material \& Methods}

60 women with valid legal indications as per MTP Act of India for mid-trimester abortion were studied in Mahila chikisalay, SMS Medical College, Jaipur. Gestational age was determined from last menstrual period, abdominal \& bimanual examination and ultrasonography. Women having intrauterine fetal death, cervical dilatation more than $1 \mathrm{~cm}$ and length of cervix less than $3 \mathrm{~cm}$, haemoglobin less than $8 \mathrm{gm} \%$, low lying placenta, scarred uterus (previous caesarean section, previous hysterotomy / myomectomy), coagulation disorder, local vaginal lesion and multiple pregnancy were excluded from the study. Women selected by randomized method. Each group had 30 women. Group-A received intravaginal tab Misoprostol $600 \mu \mathrm{g}$ followed by $400 \mu \mathrm{g} 8$ hourly vaginally and Group-B received extra-anminotic Ethacridine lactate $0.1 \%(10$ $\mathrm{ml} /$ week of gestation, not more than $150 \mathrm{cc}$, using Foley's catheter inflated with 25cc normal saline) followed 6 hours later by vaginal tab Misoprostol $400 \mu \mathrm{g} 3$ hourly until abortion occurred or upto 48 hours. Catheter expelled out spontaneously or removed after 24 hours.

Women observed for 48 hours for spontaneous expulsion of products. In our study if no expulsion occurred in 48 hours, the cases considered as failure. In both groups after delivery of fetus, all women received 20 units of oxytocin in $500 \mathrm{cc}$ of $5 \%$ dextrose. When placenta and membranes expelled within 1 hour of expulsion of fetus, abortion considered as complete. If not, manual removal or curettage was done and the abortion was considered as incomplete. Induction-abortion interval was defined as time taken from initial instillation of drug to the complete expulsion of conceptus. Discharge of the patient was done after 24 hours of abortion, if she had no complaints.

Success rate, induction-abortion interval, type of abortion, side effects and complications and hospital stay noted. Statistical analysis was done by using unpaired't' test where appropriate.

\section{Results}

Mean age of women in our study was 25 years. $91.67 \%$ cases were Hindu and $75 \%$ were literate. Most women came from urban areas (66.67\%) with mean parity 1.51 (majority were Para 1 and Para 2) and mean gestational age 16.8 weeks. Main indication of MTP was on Medical grounds followed by Eugenic then Social grounds.In mean induction-abortion interval in Group-A was $24.9 \pm 10.83$ hours and in Group-B it was $18.3 \pm$ 6.1 hours [P-value was 0.0063 statistically significant] (as shown in table 1). Thus, induction-abortion interval was significantly less in the Ethacridine lactate + Misoprostol group (B) than the Misoprostol alone group(A) . Complete abortions occurred in $83.33 \%$ of cases of Group-B v/s $70 \%$ cases of Group-A. Therefore, incomplete abortions were less in Group-B than Group-A (16.67\% v/s 23.33\%). Failure rate in Group-A was $6.67 \%$ while none in Group-B (as shown in table 2). The efficacy of abortion is higher (100\%) in Ethacridine lactate + Misoprostol group as compared to Misoprostol alone group [93.33\%] ( as shown in table 3). In this study side effects and complications were more common in Misoprostol alone group than Ethacridine lactate + Misoprostol group. Cramping abdominal pain, nausea and fever were more common side effects in Group-A than Group-B. Complications like cervicovaginal tear and uterine haemorrhage requiring blood transfusion were $6.66 \%$ in Group-A as compared to nil in Group-B (as shown in table 4).Our study shows that in Group-B mean hospital stay was $48.53 \pm 8.73$ hours which was significantly lesser than in Group-A (57.30 \pm 16.77 hours) as shown in table 5. Thus, Ethacridine lactate + Misoprostol regimen reduces hospital stay as well as mental stress to the patient.

\section{Discussion}

Ethacridine lactate for midtrimester abortion has a long history of use in our country and its safety has documented. There are no apparent contraindications for its use. Its use alone has certain disadvantages like longer induction abortion interval, higher failure rate and more chances of incomplete abortion. However, by combining Ethacridine lactate with tab Misoprostol per vaginally these disadvantages has largely overcome leading to shorter induction abortion time and higher success rates in terms of complete abortion. Hence, this regime is now better alternative for either agent used alone. Biswas Subhash Chandra, Dey Ramprasad et al $(2007)^{3}$ randomized 50 women for mid-trimester termination of pregnancy (13-20 weeks) in 2 groups. Group I $600 \mu \mathrm{g}$ Misoprostol was given vaginally followed by $400 \mu \mathrm{g} 8$ hourly upto maximum 48 hours. In Group II $150 \mathrm{ml}$ of Ethacridine was instilled extraamniotically. Misoprostol was found to be $92 \%$ effective as compared to Ethacridine with $80 \%$ effectiveness. Mean induction-abortion interval was 13.94 hours in Group I v/s 28.86 hours in Group II. In Group I 84\% aborted within 24 hours and 92\% within 36 hours whereas in Group II 16\% aborted within 24 hours and 68\% within 36 hours. 32\% women in Group I and 44\% in Group II experienced complications. Hence used alone, Misoprostol is safer, more effective and acceptable than Ethacridine for midtrimester pregnancy termination. Chaudhuri Snehamay et al (2006) ${ }^{6}$ studied 120 women between 13 to 20 weeks seeking for termination of pregnancy. Women were randomized in 2 groups. In one group extraamniotic Ethacridine lactate $(10 \mathrm{ml} /$ week of gestation) instillation was done and in the other group, $400 \mu \mathrm{g}$ Misoprostol was inserted vaginally 12 hourly for a maximum of 4 doses. Rate of successful abortions within 48 hrs was $95 \%$ 
(57/60) in each group. The mean induction-abortion interval was shorter in Misoprostol group (15.4 hours v/s 31.3 hours, $\mathrm{p}<0.0001)$. The rate of complete abortion was $66.6 \%$ for Misoprostol and $70 \%$ for ethacridine lactate. Side effects were uncommon and did not differ between the two groups. This study shows shorter mean abortion time on using Misoprostol $400 \mu \mathrm{g} 12$ hourly than our study. This probably is due to the larger sample size studied by Chaudhuri Snehamay et al. Tayade SA et al (2011) ${ }^{7}$ compared the efficacy of Misoprostol alone and Ethacridine lactate for first and second trimester abortions. 120 women desirous of MTP were randomized into two groups. In Group-A $(\mathrm{n}=42)$ Ethacridine lactate $10 \mathrm{ml} / \mathrm{wk}$ was instilled extra-amniotically after adding $200 \mu \mathrm{g}$ Misoprostol to it followed by $200 \mu \mathrm{g}$ Misoprostol was inserted intravaginally 2 hourly upto 4 doses. Group-B ( $\mathrm{n}=78$ ) received only $200 \mu \mathrm{g}$ Misoprostol intravaginally 2 hourly upto maximum 5 doses. Results of their study made conclusion that Misoprostol has the ability to interrupt pregnancy at any gestational age and addition of Ethacridine lactate enhances the efficacy of Misoprostol for first and second trimester induced abortion without undue complications. Prostaglandins when used with Ethacridine lactate have synergistic effect with endogenous prostaglandins released due to stripping of membranes from extra-amniotic Ethacridine lactate instillation.

\section{Conclusion}

Both Misoprostol alone or Ethacridine lactate with Misoprostol are effective in mid-trimester termination of pregnancy. Our study concludes that Ethacridine lactate followed by Misoprostol is more effective, safer, and with lesser side effects and complications, acceptable and has less induction-abortion interval than Misoprostol alone.So it should be the method of choice for mid-trimester termination of pregnancy.

\section{Reference}

[1]. Dr. Reeta Mohan and Prof. RS Goyal. The changing pattern of medical termination of pregnancy in Rajasthan and India, April 2000; Vol. 46, No. 1

[2]. Nagaria Tripti, Sirmor Namrata. Intravaginal Misoprostol for termination of second trimester pregnancy. J Obs \& Gynae India, Sept/Oct 2007, Vol. 57, No. 5 : 435-438.

[3]. Biswas Subhash Chandra, Dey Ram Prasad, Rajaram J, Nibedita C. Comparative study of intravaginal misoprostol and extramniotic ethacridine lactate instillation for mid trimester termination of pregnancy. J obst \& Gynaeco India, May/June 2007; Vol. 57, No. 3 : 210-212.

[4]. Shipra Kunwar, Pradip K Saha, Poonam Goel, Anju H, Rimpi H, Alka S. Second trimester pregnancy termination with 400 Mg vaginal misoprostol : Efficacy and safety. Bioscience Trends, 2010; 4(6) : 351-354.

[5]. S Lalit Kumar, M Bygdeman and K Genzell Danielsson. Mid-trimester induced abortion : A review. Human Reproduction Update, 2007; Vol. $13: 37-52$

[6]. Snehamay C, Nath MS, Nilanjana C, Debasish C, Debdut B, Sudipta B. A comparison of IV misoprostol with EA-EL for second trimester MTP. J Obst Gynae India, 2006; 56(6) : 518-521.

[7]. Tayade SA, Samal S, Tayade AT. Prostaglandin analogues and ethacridine lactate for first and second trimester induced abortion. Int J Biol Med Res, 2011; 2(4) : 1075-1077.

Table - 1

Induction-Abortion Interval in Two Groups

\begin{tabular}{|l|l|l|l|l|}
\hline \multirow{2}{*}{$\begin{array}{l}\text { Induction-Abortion Interval } \\
\text { in hours) }\end{array}$} & Group-A & Group-B \\
\cline { 2 - 5 } & No. & $\mathbf{\%}$ & No. & \% \\
\hline $\mathbf{0 - 6}$ & 0 & 0.00 & 0 & 0.00 \\
\hline $\mathbf{6}-\mathbf{1 2}$ & 2 & 6.67 & 6 & 20.00 \\
\hline $\mathbf{1 2}-\mathbf{1 8}$ & 8 & 26.66 & 12 & 40.00 \\
\hline $\mathbf{1 8}-\mathbf{2 4}$ & 5 & 16.67 & 8 & 26.66 \\
\hline $\mathbf{2 4}-\mathbf{3 0}$ & 7 & 23.33 & 2 & 6.67 \\
\hline $\mathbf{3 0}-\mathbf{3 6}$ & 4 & 13.33 & 2 & 6.67 \\
\hline $\mathbf{3 6}-\mathbf{4 2}$ & 2 & 6.67 & 0 & 0.00 \\
\hline $\mathbf{4 2}-\mathbf{4 8}$ & 0 & 0.00 & 0 & 0.00 \\
\hline Failure & 2 & 6.67 & 0 & 0.00 \\
\hline Total & $\mathbf{3 0}$ & $\mathbf{1 0 0 . 0 0}$ & $\mathbf{3 0}$ & $\mathbf{1 0 0 . 0 0}$ \\
\hline
\end{tabular}

Mean $\pm S D($ Group $-A)=24.9 \pm 10.83$ hours

Mean $\pm S D($ Group $-B)=18.3 \pm 6.1$ years

$P$-value $=0.0063$ (Significant)

Table - 2

Type of Abortion in Both Groups

\begin{tabular}{|l|l|l|l|l|}
\hline \multirow{2}{*}{ Type of Abortion } & Group-A & Group-B \\
\cline { 2 - 5 } & No. & \% & No. & \% \\
\hline Complete Abortion & 21 & 70.00 & 25 & 83.33 \\
\hline Incomplete Abortion & 7 & 23.33 & 5 & 16.67 \\
\hline Failure of Abortion & 2 & 6.67 & 0 & 0.00 \\
\hline Total & $\mathbf{3 0}$ & $\mathbf{1 0 0 . 0 0}$ & $\mathbf{3 0}$ & $\mathbf{1 0 0 . 0 0}$ \\
\hline
\end{tabular}


Table - 3

Efficacy of Abortion in Two Groups

\begin{tabular}{|l|l|l|l|l|}
\hline \multirow{2}{*}{ Efficacy of Abortion } & Group-A & Group-B \\
\cline { 2 - 5 } & No. & \% & No. & \% \\
\hline Abortion & 28 & 93.33 & 30 & 100.00 \\
\hline Failure & 2 & 6.67 & 0 & 0.00 \\
\hline Total & $\mathbf{3 0}$ & $\mathbf{1 0 0 . 0 0}$ & $\mathbf{3 0}$ & $\mathbf{1 0 . 0 0}$ \\
\hline
\end{tabular}

Table -4

Comparison of Side Effects and Complications in Both Groups

\begin{tabular}{|l|l|l|l|l|}
\hline \multirow{2}{*}{$\begin{array}{l}\text { Side Effects and } \\
\text { Complications }\end{array}$} & $\begin{array}{l}\text { Group-A } \\
(\mathbf{n = 3 0})\end{array}$ & $\begin{array}{l}\text { Group-B } \\
(\mathbf{n = 3 0})\end{array}$ \\
\cline { 2 - 5 } & No. & $\%$ & No. & $\%$ \\
\hline Side Effects & & & & \\
\hline 1. Cramping Abdominal Pain & 6 & 20.00 & 3 & 10.00 \\
\hline 2. Nausea & 6 & 20.00 & 4 & 13.33 \\
\hline 3. Vomiting & 2 & 6.67 & 1 & 3.33 \\
\hline 4. Diarrhoea & 1 & 3.33 & 0 & 0.00 \\
\hline 5. Fever / Chills & 5 & 16.67 & 2 & 6.67 \\
\hline Complications & & & & \\
\hline 1. Cervico Vaginal Tear & 1 & 3.33 & 0 & 0.00 \\
\hline 2. Blood Transfusion & 1 & 3.33 & 0 & 0.00 \\
\hline 3. Rupture Uterus & 0 & 0.00 & 0 & 0.00 \\
\hline
\end{tabular}

Table - 5

Hospital Stay in Both Groups

\begin{tabular}{|l|l|l|l|l|}
\hline \multirow{2}{*}{$\begin{array}{l}\text { Hospital Stay } \\
\text { in hours) }\end{array}$} & Group-A & Group-B \\
\cline { 2 - 5 } & No. & \% & No. & \% \\
\hline $\mathbf{2 4 - 3 6}$ & 0 & 0.00 & 0 & 0.00 \\
\hline $\mathbf{3 7}-\mathbf{4 8}$ & 13 & 43.33 & 21 & 70.00 \\
\hline $\mathbf{4 9}-\mathbf{6 0}$ & 8 & 26.67 & 6 & 20.00 \\
\hline $\mathbf{6 1}-\mathbf{7 2}$ & 5 & 16.67 & 2 & 6.67 \\
\hline $\mathbf{7 3 - 8 4}$ & 1 & 3.33 & 1 & 3.33 \\
\hline $\mathbf{8 5}-\mathbf{9 6}$ & 1 & 3.33 & 0 & 0.00 \\
\hline$>\mathbf{9 6}$ & 2 & 6.67 & 0 & 0.00 \\
\hline Total & $\mathbf{3 0}$ & $\mathbf{1 0 0 . 0 0}$ & $\mathbf{3 0}$ & $\mathbf{1 0 0 . 0 0}$ \\
\hline
\end{tabular}

Mean \pm SD (Group-A) $=57.30 \pm 16.77$ hours

Mean \pm SD $($ Group-B $)=48.53 \pm 8.73$ hours

$\mathrm{P}$-value $=0.0147(\quad$ Significant $)$ 